\title{
Medical Management of Post-Operative Abdominal Infection: A Case of Well Management and Appropriate Medications
}

\author{
Amer Hayat Khan ${ }^{1}$, Andee Dzulkarnaen Zakaria ${ }^{2}$, Syed Hassan², Ashfaq Ahmad ${ }^{1 *}$ and Mohamed Azmi Hassali ${ }^{1}$ \\ ${ }^{1}$ School of Pharmaceutical Sciences, Universiti Sains Malaysia \\ ${ }^{2}$ Department of Surgery, School of Medical Sciences, Universiti Sains Malaysia, Health Campus Kelantan, Malaysia
}

\section{Abstract}

A 55 years old man was presented with abdominal pain and even distension. Patient was admitted from clinic for persistent pus discharge from wound suture. Present case is established case of hypertension, colon cancer, familial adenomatous polyposis and liver metastases changes stage four (post panproctocolectomy with ileoanal anastomosis with ileal pouch and disfunctioning ileastases). Operation procedure is done with multiple liver nodule, tumor sigmoid and descending colon while small bowel and stomach was normal. After 2 months of surgical procedure, patient's pus discharge was confirmed with presence of mixed growth of gram negative bacilli and gram positive cocci.

To improve the prognosis of patient with intra abdominal infection, monitoring of wounds, examination of tissue or pus discharge and proper selection of antibiotic treatment must be practicized. The bacteria inoculums must be controlled and diminished in the most effective manner depending on the patient condition. Mechanistic approach of surgeon and professional attitude may retard the accelerated prognosis of post operative intra-abdominal infections of the cancer patient.

Keywords: Sepsis; Hypertension; Familial adenomatous polyposis; Ileoanal anastomosis

\section{Introduction}

Intra-abdominal infections are the most complicated infections to diagnose and treatment. A successful outcome depends upon early diagnosis, rapid, appropriate surgical intervention and also the selection of most appropriate antibiotics [1]. The tertiary infections are relatively new term which is referring to those patients who require more than one operation for infection source control [2]. Complicated intra-abdominal infection is a common problem with appendicitis alone affecting about 300,000 patients per year and consuming more than one million hospital days. Intra abdominal infection is the second most common cause of infectious mortality in the intensive care unit. The requirement for intervention in most cases and the controversies surrounding the choice and nature of the procedure performed has added another layer of complexity to the management of these patients [3]. The possible complications for abdominal infections include the return of the abscess, rupture of an abscess, spread of the infection to the bloodstream (sepsis), widespread infection in the abdomen [4].

Surgeon commonly deals with intra-abdominal infections that are the result of perforation of a hollow viscous, which lead to three potential outcomes: clearance of the bacteria by the host, abscess formation and peritonitis [2]. Infection is established if the quantity and virulence of the bacteria over run local peritoneal host defenses include resident peritoneal macrophages, early neutrophil recruitment, as well as activation of the coagulation and complement cascades. If host defenses are completely overwhelmed, then diffuse peritonitis will result. An abscess will form after fibrin deposition [2]. Present case study designed to highlight the well management of surgical complications with appropriate selection of medications and accurate diagnosis can save patient from life threatening conditions.

\section{Case Report}

A 55 years old man was presented with abdominal pain and abdominal distension and was admitted from clinic for persistent pus discharge from wound suture after one and half month of surgical procedure. Upon history, it appeared that antibiotic used were not of broad spectrum (first generation cephalosporin ampicillins). He was known case of hypertension, colon cancer, familial adenomatous polyposis and liver metastases changes stage four (post panproctocolectomy with ileoanal anastomosis with ileal pouch and defunctioning ileastases). Patient under went with second suturing after 20 days of $1^{\text {st }}$ surgery. Previous operation procedure was done due to multiple liver nodules, tumor sigmoid and descending colon while his small bowel and stomach was normal.

Based on the laboratory data received, patient haemoglobin was below than the normal value for male and his white blood cell was higher than normal range. Thus, doctor started haematinic agents to improve patient blood volume and doctor also started IV cefoperazone ( $3^{\text {rd }}$ generation cephalosporin) $1 \mathrm{~g}$ and IV metronidazole $500 \mathrm{mg}$. CT scan done after $2^{\text {nd }}$ surgical procedure which showed multiple intraabdominal collection. Physical examination showed patient abdominal was soft and non-tender. Pus was tested with presence of mixed growth of gram negative bacilli and lumbar drain was yellow to greenish colour. After seven days of therapy, pus examination further confirmed the presence of mixed growth of gram negative bacilli and gram positive cocci. CT scan done in successive diagnostic procedure, showed that possibility of leakage at ileoanal anastomosis and enterocutaneous fistula. It was expected that the leak part was not yet settled.

*Corresponding author: Ashfaq Ahmad, School of Pharmaceutical Sciences, Universiti Sains Malaysia,Penang 11800, Malaysia, E-mail: amerhayat@ymail.com

Received January 22, 2013; Accepted March 22, 2013; Published March 26 , 2013

Citation: Khan AH, Zakaria AD, Hassan S, Ahmad A, Hassali MA (2013) Medical Management of Post-Operative Abdominal Infection: A Case of Well Management and Appropriate Medications. Trop Med Surg 1: 110. doi:10.4172/2329-9088.1000110

Copyright: (C) $2013 \mathrm{Khan} \mathrm{AH}$, et al. This is an open-access article distributed under the terms of the Creative Commons Attribution License, which permits unrestricted use, distribution, and reproduction in any medium, provided the original author and source are credited. 


\begin{tabular}{|l|l|}
\hline Tablet cefuroxime & $250 \mathrm{mg}$ twice daily \\
\hline Tablet metronidazole & $400 \mathrm{mg}$ thrice daily \\
\hline Tablet ferrous fumarate & Once daily \\
\hline Tablet folic acid & Once daily \\
\hline Tablet B complex & Once daily \\
\hline Tablet multivitamin & Once daily \\
\hline Tablet gliclazide & $80 \mathrm{mg}$ twice daily \\
\hline
\end{tabular}

Patient was also given dressing Kalfostat (calcium sodium alginate) and dermasyn (hydrogel wound dressing)

Table 1: Medications on discharged

\begin{tabular}{|l|l|}
\hline Regimen & $\begin{array}{l}\text { Imipenem/cilastatin } \\
\text { Meropenem } \\
\text { Piperacillin/tazobactam }\end{array}$ \\
\hline Combination therapy & $\begin{array}{l}\text { Aminoglycoside (amikacin, gentamicin, netilmicin, } \\
\text { tobramycin) plus an anti-anaerobe (clindamycin or } \\
\text { metronidazole) Aztreonam plus clindamycin } \\
\text { Ciprofloxacin plus metronidazole }\end{array}$ \\
\hline Combination therapy & $\begin{array}{l}\text { Third/fourth generation cephalosporin (cefepime, } \\
\text { cefotaxime, ceftazidime, ceftizoxime, ceftriaxone) plus an } \\
\text { anti-anaerobe (clindamycin or metronidazole) }\end{array}$ \\
\hline
\end{tabular}

Table 2: Recommended antimicrobial regimens for high-risk patients with intraabdominal infection.

\begin{tabular}{|l|l|l|}
\hline Pathogen & Drug(s) & $\begin{array}{l}\text { Country (years) } \\
\text { reference }\end{array}$ \\
\hline $\begin{array}{l}\text { Mycobacterium } \\
\text { tuberculosis }\end{array}$ & $\begin{array}{l}\text { Isoniazid, Streptomycin, } \\
\text { Rifampicin, (Primary Resistance) }\end{array}$ & $\begin{array}{l}\text { Kenya (1981-1990) [12] } \\
\text { Morocco (1992-1994) [13] }\end{array}$ \\
\hline $\begin{array}{l}\text { Enterotoxigenic } \\
\text { Escherichia coli }\end{array}$ & Cotrimethoxazole & Thailand (1981-1995) [14] \\
\hline $\begin{array}{l}\text { Vibrio cholerae } \\
\text { Guinea-Bissau }\end{array}$ & Cotrimethoxazole, Nalidixic & $(1987-1995)[15]$ \\
\hline $\begin{array}{l}\text { Shigella flexneri, } \\
\text { Bangladesh }\end{array}$ & $\begin{array}{l}\text { Ampicillin, Tetracycline, } \\
\text { Sulfonamides }\end{array}$ & $(1983-1990)[16]$ \\
\hline
\end{tabular}

Table 3: Prevalence of increase resistance in developing countries.

Currently patient was conscious and alert, a febrile. His blood pressure was normal and his blood glucose level was slight higher than normal range. Albumin level in this patient is normal. Patient was discharged and advised to go clinic every day for drainage purpose and come again after two weeks. Patient was recovered after 2 weeks daily dressing and aggressive use of antibiotics.

\section{Discussion}

Generally the diagnosis of intra-abdominal infection is made on physical examination. Before abdominal CT was readily available, it was much more difficult to diagnose intra-abdominal infections and the diagnosis was often delayed. The treatment of intra-abdominal infections is predicated on restoration of normal homeostasis. The principles of treatment include: restoration of fluid and electrolyte imbalances; physiologic support of organ systems; administration of appropriate empiric antimicrobial therapy and control of the source of the infection [5].

Regarding present case, IV drip was maintained to improve their electrolytes imbalance. 5 pints of IV drip which are four normal saline drips $(0.9 \% \mathrm{NaCl})$ and one $5 \%$ dextrose for one day. Haematinic agents such as tablet folic acid, tablet ferrous fumarate, tablet B complex and tablet multivitamin were given to the patient to improve haemoglobin level. Counseling point such as appearance of black colour stool need to aware the patient.

Antibiotic treatment includes metronidazole and cefoperazone. Numbers of regimen are available with compareable efficacy [6].
According to a research, metronidazole has been used by many investigators, particularly in Europe. This drug has excellent activity against most anaerobic organism [7]. It's of great concern that elderly patient has familial adenomatous polyposis and liver metastases changes (stage four), and used of metronidazole in severe liver impairment patient may bring to potential accumulation. Thus, the liver function test for this patient is highlighted. Reduced dose is recommended for this patient. Apart from that, the test investigations may interfere by metronidazole such as glucose level, LDH testing [8].

Bacterial resistance is common in healthy isolates and person with community acquired infections in developing countries and prevalence of highly infectious disease the need for antibiotic is inevitable [9].

The used of third generation antibiotic (cefeperozole) and metronidazole are alternatives for microbial resistance or when nephrotoxicity is a concern. Tablet cefuroxime was prescribed. The most common adverse reaction of cefuroxime is nausea and vomiting (4\%-11\%) [8]. Here choice of Lincosamide group like lincomycin or clindamycin with metronidazole in discharge medicine may reduce post operative complication as combination therapy will cover all the gram positive and negative anaerobes and aerobes. Clindamycin is generally employed in infection caused by anaerobic bacteria like Bacteroides fragilis which often causes abdominal infections associated with trauma [10]. Blood glucose level of patient is higher than the normal so there is susceptibility of complication in healing of wounds. Clindamycin has ability to penetrate in poor blood supply areas of body and can be considered as drug of choice in these cases. So combination therapy of Clindamycin and metronidazole should be recommended in serious infections [10].

In addition, another point of concern was patient blood glucose level is higher than normal range $(<7 \mathrm{mmol})$. At the time of discharge his blood glucose level was $10.1 \mathrm{mmol}$. Counseling on diet is needed. On the other hand, patient is known case of high blood pressure, prescribed amlodipine $10 \mathrm{mg}$ daily. He had stopped taking antihypertensive agent. This may due to his blood pressure level is normalized $(<130 / 90 \mathrm{mmHg})$.

A deep point of concern was leakage part at abdominal is not yet settled and patient was discharged. The high white blood cell is also a complication in this patient. Patent high white blood cells value is not improved from day of admission until the day of discharged. It can be perceived that present case is high risk case of sepsis will occur. Based on studies, advanced age, comorbidity and degree of organ dysfunction, inability to achieve adequate debridement or control, low albumin level, poor nutritional status and presence of malignancy will increase the rate of treatments failure in patient [11] [Tables 1-3]. Counseling for patient such as must attend clinic every day for drainage purpose, always keep his body clean and healthy.

\section{Conclusion}

Thus, in conclusion, to improve the prognosis of patient with intra abdominal infections, monitoring and culture examination of tissue or discharge and proper selection of antibiotic [12-16] must be practisized. Furthermore, the bacteria inoculums must be controlled and diminished in the most effective manner depending on the patient condition. During the treatment number of complications like age, malignancy, impaired liver, pus leakage from peritoneum to body, hypertension and diabetes were handled in mechanistic and professional approach. So this case report is a kind of medical education and successful handling of complicated case with number of comorbidities. 
Citation: Khan AH, Zakaria AD, Hassan S, Ahmad A, Hassali MA (2013) Medical Management of Post-Operative Abdominal Infection: A Case of Well Management and Appropriate Medications. Trop Med Surg 1: 110. doi:10.4172/2329-9088.1000110

Page 3 of 3

\section{References}

1. Clinical update in infectious diseases. Intra-abdominal infections-A surgical perspective (1996) 111: 1 .

2. Cheadle WG, Spain DA (2003) The continuing challenge of intra-abdominal infection. Am J Surg 186: 15S-22S.

3. Solomkin JS, Mazuski JE, Bradley JS, Rodvold KA, Goldstein, et al. (2010) Diagnosis and management of complicated intra-abdominal infection in adults and children: Guidelines by the surgical infection society and the infectious diseases society and the infectious diseases society of America. Clin Infect Dis 50: $133-164$.

4. Intra-abdominal abscess. Updated by David C. Dugdale.

5. Malangoni MA (2005) Contributions to the management of intraabdomina infections. Am J Surg 190: 255-259.

6. Mazuski JE, Sawyer RG, Nathens AB, Dipiro JT, Schein M, et al. (2002) The surgical infection society guidelines on antimicrobial therapy for intra-abdominal infections: an executive summary, Surg. Infect 3: 161-173

7. Gorbach SL (1993) Treatment of intra-abdominal infections. J Antimicrob Chemother 31 Suppl A: 67-78.

8. Lexi-comp's drug references handbooks. Drug information handbook with international trade names index. $19^{\text {th }}$ edition. 2010-2011

9. Kunin CM (1993) Resistance to antimicrobial drugs--a worldwide calamity. Ann Intern Med 118: 557-561.
10. Guirao X, Arias J, Badía JM, García-Rodríguez JA, Mensa J, et al. (2009) [Recommendations in the empiric anti-infective agents of intra-abdominal infection]. Rev Esp Quimioter 22: 151-172.

11. Avery B. Nathens, Ori D. Rotstein (1996) Antimicrobial therapy intraabdominal infection. The American journal of surgery 172: 1-6.

12. Githui WA, Kwamanga D, Chakaya JM, Karimi FG, Waiyaki PG (1993) Antituberculous initial drug resistance of Mycobacterium tuberculosis in Kenya: a ten-year review. East Afr Med J 70: 609-612.

13. el Baghdadi J, Lazraq R, Ibrahimy S, Bouayad Z, Guinet R, et al. (1997) Survey of primary drug resistance of Mycobacterium tuberculosis in Casablanca, Morocco. Int J Tuberc Lung Dis 1: 309-313.

14. Hoge CW, Gambel JM, Srijan A, Pitarangsi C, Echeverria P (1998) Trends in antibiotic resistance among diarrheal pathogens isolated in Thailand over 15 years. Clin Infect Dis 26: 341-345.

15. Dalsgaard A, Mortensen HF, Mølbak K, Dias F, Serichantalergs O, et al. (1996) Molecular characterization of Vibrio cholerae $\mathrm{O} 1$ strains isolated during cholera outbreaks in Guinea-Bissau. J Clin Microbiol 34: 1189-1192.

16. Bennish ML, Salam MA, Hossain MA, Myaux J, Khan EH, et al. (1992) Antimicrobial resistance of Shigella isolates in Bangladesh, 1983-1990: increasing frequency of strains multiply resistant to ampicillin, trimethoprimsulfamethoxazole, and nalidixic acid. Clin Infect Dis 14: 1055-1060. 